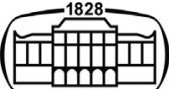

AKADÉMIAI KIADÓ

\title{
A scoping review of hard systems and tools that restrict money and cash for gambling
}

\author{
SIMONE N RODDA ${ }^{1,2 *} \odot$
}

\section{Journal of Behavioral Addictions}

10 (2021) 3, 587-600

DOI:

$10.1556 / 2006.2021 .00065$

(c) 2021 The Author(s)

\section{REVIEW ARTICLE}

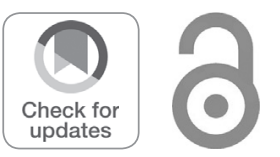

* Corresponding author

E-mail: s.rodda@auckland.ac.nz

\author{
${ }^{1}$ School of Population Health, University of Auckland, Private Bag 92019, Auckland 1142, \\ New Zealand \\ ${ }^{2}$ School of Psychology, Deakin University, Geelong, Australia
}

Received: May 29, 2021 • Revised manuscript received: August 19, 2021 • Accepted: August 21, 2021

Published online: September 17, 2021

\begin{abstract}
Background: Gamblers engage in a range of "soft" financial options to limit access to money or cash for gambling (e.g., family looks after cash). Such barriers are easily overturned, resulting in a demand for financial systems and tools that offer "hard" restrictions on access to money and cash in a gambling context. The aim of this scoping review was to determine the attitudes and preferences of gamblers and their families on systems or tools to restrict access to money and cash, as well as the effectiveness of systems and tools that can be used to accomplish that goal. Methods: A systematic search of articles related to financial restrictions and gambling was conducted. Eligibility criteria included samples of gamblers or affected others and interventions targeted at money or cash restrictions in a gambling context. Soft financial barriers such as family involvement were excluded, as were limit-setting systems which focused on gambling expenditure in gambling venues. Results: Nine studies met the eligibility criteria, with three focused on financial systems (e.g., ban on credit betting) and six focused on removal of cash machines from gambling venues. The included literature was generally of low quality, with just two pre-post studies and seven cross-sectional or qualitative ones. Conclusions: The included studies provided strong support for financial mechanisms to support gamblers and their families. Future studies need to involve multiple stakeholders to provide this type of support as well as to evaluate the holistic impact that such hard barriers can have on gambling and gambling-related harms.
\end{abstract}

\section{KEYWORDS}

gambling, banking, self-help, harm reduction, financial mechanisms, consumer protection

\section{INTRODUCTION}

Gambling involves the betting or wagering of something of value where the outcome is determined by chance. Usually the item of value is monetary and the motivation for gambling is primarily financial gain (Williams, Volberg, Stevens, Williams, \& Arthur, 2017). The central involvement of money means winning and losing can prompt feelings of elation and joy as well as desperation, sadness and despair heightened by a sense of financial gain or loss. To date, regulation that is specific to the monetary aspects of gambling has been tightly focused on regulation that prevents criminal activities (e.g., money laundering, loan sharks) as well as restrictions to cash and credit betting (Delfabbro \& King, 2020). There has also been a focus on supporting responsible gambling (RG) described as industry initiatives and government regulations that support people to "gamble within affordable limits" (Blaszczynski, Shaffer, Ladouceur, \& Collins, 2021). An abundance of research has been conducted on how to limit or restrict gambling expenditure. Studies have examined expenditure limits on gambling products, generation of account history, notifications of gambling expenditure, self-assessment, pop-up messages, pre-commitment, expense calculators, online surveillance, pre-paid cards and the use of e-wallets and cryptocurrencies (Blaszczynski et al., 2011, 2021; Forsström, Spångberg, Petterson, Brolund, \& Odeberg, 2020; Ladouceur, Shaffer, Blaszczynski, \& Shaffer, 2017; Lucar, Wiebe, \& Philander, 2013; 
McMahon, Thomson, Kaner, \& Bambra, 2019; Tanner, Drawson, Mushquash, Mushquash, \& Mazmanian, 2017). These studies suggest some approaches may be helpful for setting or sticking to gambling expenditure limits for some gamblers.

Gambling-related debt is an especially difficult burden for gamblers and their families. It is estimated that around one-quarter of people who develop gambling problems experience gambling-related debt (Swanton \& Gainsbury, 2020b). Debt has been associated with poor mental health, suicidality, stress, psychological distress and relationship conflict (Barnard et al., 2014; Håkansson \& Widinghoff, 2020; Muggleton et al., 2021; Oksanen, Savolainen, Sirola, \& Kaakinen, 2018; Swanton \& Gainsbury, 2020a, 2020b). In an attempt to relieve harm, gamblers may seek financial advice, which is a key motivator for treatment-seeking (Evans \& Delfabbro, 2005; Pulford et al., 2009; Suurvali, Hodgins, \& Cunningham, 2010; Suurvali, Hodgins, Toneatto, \& Cunningham, 2012). For example, $91 \%$ of women and $80 \%$ of men who called the Michigan Gambling Helpline reported difficulties in paying bills, debt and borrowing from family and credit agencies (Ledgerwood, Wiedemann, Moore, \& Arfken, 2012). Most jurisdictions offer financial assistance in the form of specialist gambling financial counsellors as well as other financial advisors (Sacco et al., 2019). Affected others may also seek advice from gambling counsellors and financial counsellors (Kalischuk, Nowatzki, Cardwell, Klein, \& Solowoniuk, 2006; Kourgiantakis, Saint-Jacques, \& Tremblay, 2013).

Recognition of the importance of gambling-related financial harm has resulted in gambling expenditure being a main outcome of interest in intervention studies (Pickering, Keen, Entwistle, \& Blaszczynski, 2018; Walker et al., 2006). However, there are few interventions that focus specifically on money (i.e., banking systems or tools) or cash management. Granero et al. (2020) examined the impact of Cognitive Behavioral Therapy (CBT) aimed at enhancing money and cash control. Participants that implemented control strategies reported lower gambling severity at posttreatment evaluation than those who did not implement the recommended approach. Treatment that focuses on money management is not just limited to gambling (Rosen, Bailey, \& Rosenheck, 2003; Rosen, Carroll, Stefanovics, \& Rosenheck, 2009). Multiple studies indicate that monetary expenditure may also be a cue for alcohol and illicit drug use (O’Brien, Childress, McLellan, \& Ehrman, 1990; Shaner et al., 1995).

More than a dozen studies have indicated that money and cash control appears to be a common self-help strategy for gambling reduction (Currie et al., 2020; Drawson, Tanner, Mushquash, Mushquash, \& Mazmanian, 2017; Hing, Russell, \& Hronis, 2017; Hing, Sproston, Tran, \& Russell, 2017; Hodgins \& El-Guebaly, 2004; Lostutter, Lewis, Cronce, Neighbors, \& Larimer, 2014; Matheson et al., 2019; Procter, Angus, Blaszczynski, \& Gainsbury, 2019; Rodda et al., 2017; Rodda, Bagot et al., 2018a; Rodda, Hing et al., 2018; Rodda, Bagot, Manning, \& Lubman, 2019a, 2019b). These studies all indicate that gamblers go to elaborate lengths to control money and cash as a way of protecting themselves and their families from unplanned or excessive gambling. Studies have reported the use of self-initiated money and cash control strategies before gambling (e.g., set a budget; leave cash or cards at home; pay bills before gambling), during gambling (e.g., avoid borrowing money; avoid cash machine use) and after gambling (e.g., avoid chasing losses) (Hing, Sproston et al., 2017; Rodda, Bagot, Manning, \& Lubman, 2019b). A factor analysis of 489 current or past gamblers reported money management was used more frequently by problem gamblers than no/low/moderate-risk gamblers; however, cash control was used equally by all gamblers (Rodda, Bagot et al., 2018). Multiple studies reported that affected others (partners, family) also apply self-help strategies regarding money management to minimise the impact of gamblingrelated harm (Booth et al., 2021; Côté, Tremblay, JiménezMurcia, Fernàndez-Aranda, \& Brunelle, 2019; Krishnan \& Orford, 2002). Such strategies include establishing signatories to joint accounts through to taking over control of the gambler's finances.

Whether money and cash control approaches are supported by formal systems or tools in a gambling context is unclear. Given that research has reported for more than 30 years that unrestricted access to money and cash is associated with gambling problems, it is timely to determine the extent to which systems and tools provide hard barriers to prevent excessive, unplanned or uncontrolled access to money or cash which could be used for gambling. Hard financial barriers refer to tools or systems that can restrict access to cash (i.e., banknotes, physical money) and money (i.e., both physical money and virtual money) which could be used for gambling. Systems and tools are formal methods to restrict access to money or cash and may be part of banking or financial management systems inside or outside the gambling venue. Almost all research to date on financial barriers to gambling has focused on soft systems such as the involvement of family members (e.g., someone else controls money or cash), voluntary in-the-moment personal restrictions (e.g., cash or debit cards left at home) as well as ways to avoid borrowing money for gambling from friends or relatives. Other research has focused on limiting gambling expenditure (limit setting, pop-up messaging), but these approaches are not intended to stem the flow of money or cash more broadly.

Prior research has recommended systems or tools that might support setting limits on hard money or cash (Barnard et al., 2014; Gambling Commission, 2020; Gambling Research Exchange Ontario, 2020; Håkansson \& Widinghoff, 2020; Muggleton et al., 2021; Oakes, Pols, \& Lawn, 2020; Swanton \& Gainsbury, 2020b; Swanton, Gainsbury, \& Blaszczynski, 2019). These include (a) banking blocks on gambling that cannot be easily overturned, (b) advocacy and grassroots campaigns for government-legislated mechanisms, (c) restriction to all credit card gambling imposed by government and the banking sector, (e) prevention of gambling expenditure by minors based on bank account information, (f) removal of ATMs (referred to as 'cash machines' in the UK) from gambling premises, (g) spend 
controls on gambling within gaming (often part of parental controls), (h) policy and regulation related to access to money and cash for gambling, (i) banking accounts that can be personalised according to individual need such as no access to cash, $(\mathrm{j})$ proactive intervention from banks where high-risk gambling behaviours are identified and $(\mathrm{k})$ open access to anonymous bank transaction data for research purposes.

The primary aim of this study was to assess the presence of hard financial barriers in the context of gambling harm minimisation for anyone who gambles. The goal was to conduct a scoping review to explore systems and tools that can support those who gamble and act as a barrier to money or cash expenditure. This included identifying attitudes and preferences towards systems and tools (e.g., perceived need or benefit) as well as the effectiveness of existing systems and tools and their characteristics and target groups. Where systems and tools were identified, the review also described their content and functionality. The specific research questions were: (a) What are the characteristics of systems and tools that could be used to impose a barrier to money or cash expenditure in a gambling context? (b) What are the attitudes and preferences of gamblers and affected others towards such systems and tools? (c) Who are the target group of such systems and tools? (d) What is the effectiveness of such systems and tools? (e) Are there effective systems and tools for those at different levels of gambling risk?

\section{METHODS}

A scoping review was selected as a form of knowledge acquisition that can synthesise information to answer an exploratory research question. Given the expected limited evidence in the field, the scoping review was a preferred way to identify gaps in research, as well as systematically search, select and synthesise existing evidence (Colquhoun et al., 2014). This scoping review followed the protocols recommended in the Preferred Reporting Items for Systematic Reviews and Meta-Analyses (PRISMA) guidelines (Moher, Liberati, Tetzlaff, \& Altman, 2009).

\section{Search strategy}

A systematic search was conducted in December 2020 to identify all relevant peer-reviewed literature exploring financial systems and tools to restrict access to money or cash that could be used for gambling. The search strategy included an electronic database search of Medline, Cochrane, Scopus, PsycInfo and Proquest Dissertations and Theses Global using a combination of MeSH terms, key words and wildcards. Search terms incorporated the following terms: gambling (e.g., wagering, betting, gamble) AND finances (e.g., cash, credit, funding, bank, debt, financial, economics) AND limit (e.g., barrier, harm minimisation, harm reduction, prevention, note acceptors, consumer safety, social responsibility, ban, restriction). A grey literature search was also conducted through the GREO
Evidence Centre, as well as GambleAware, UK Gambling Commission Library, OPHLA Canada, WorldWide Science, Ontario Public Health Library Association and Social Care Online. Finally, a search was conducted using Google Scholar to detect other peer-reviewed and non-peerreviewed publications (limited to the first 100 search results). The reference lists of all included studies were searched to identify any potential studies that met the inclusion criteria as well as recent systematic and literature reviews.

\section{Eligibility criteria}

Studies were selected based on the following inclusion criteria. Studies had to: (1) include gamblers or affected others at risk of gambling harm or with problem gambling; (2) focus on systems and tools that provide hard barriers to money or cash access; (3) be targeted directly at access to money or cash (not limit-setting of gambling expenditure); (4) apply to a land-based or online gambling venue or setting (e.g., credit bans) or external setting (financial institutions); (5) include empirical data (qualitative or quantitative) and (6) be published in English language. Studies were excluded if they contained optional or nonbinding ("soft") financial barriers, such as family involvement in restricting access to money or cash. Studies were also excluded if they were not directly related to access to money or cash such as deposit limit and pre-commitment systems (these are considered limiting gambling expenditure rather than access to money or cash) or did not include empirical data (e.g., opinion pieces, legal documents).

\section{Data extraction and analysis}

Data was extracted using a standardised form that included the following characteristics: participant details, definition of hard financial limit, study design, intervention characteristics, outcome measures and significance and direction of results. The author extracted the data from all included studies. To ensure accuracy of data extraction, a second reviewer independently screened a random selection of 50 records for eligibility which resulted in no disagreement. For full-text review, the second reviewer independently reviewed five publications to ensure a high level of agreement in assessment of eligibility. Assessments of methodological quality or risk of bias of the included studies are generally not recommended for a scoping review (Peters et al., 2015). To provide an indicator of overall study quality, the current review mapped study design against the hierarchy of evidence with ratings of high (RCTs, observational studies), moderate (pre-post studies, uncontrolled trials) and low (descriptive studies, case studies, expert opinion) (Evans, 2003).

\section{Ethics}

All procedures performed in studies involving human participants were in accordance with the ethical standards of the 
institutional and/or national research committee and with the 1964 Helsinki declaration and its later amendments or comparable ethical standards.

\section{RESULTS}

A total of nine studies were identified for inclusion in the review (Fig. 1). The search of Medline, Cochrane, PsycInfo, Scopus and PDQT (dissertations and theses) databases provided a total of 1,646 citations. After accounting for duplicates, 1,184 studies remained. Of these, 1,129 studies were removed because review of the titles and abstracts indicated that these papers did not meet the study criteria. The full texts of the remaining 55 citations were examined for eligibility. Forty-six of these studies did not meet the inclusion criteria because they were not focused on hard barriers, reported no data or reported correlations only (e.g. relationship between gambling and ATM use), reported voluntary systems or tools focused on gambling expenditure or were not related to money or cash restrictions. The reference list search of the included studies identified one additional study that met the inclusion criteria. Therefore, nine studies met the inclusion criteria and were included in the scoping review. All studies were funded through government or government-funded agencies and there was no reported industry funding.

\section{Study design}

Included studies were published between 2004 and 2020. Of the nine studies, two were pre-post surveys, three crosssectional cohort and six qualitative studies using interviews or focus group methods. Two of these studies were mixed methods involving both a survey (one cohort and one prepost) and interviews (McMillen, Marshall, \& Murphy, 2004; Thomas et al., 2013). There were three studies on money management and six studies related to automated teller machines (ATM, also referred to as 'cash machines') or electronic funds transfer point of sale (EFTPOS; also referred to in the UK as a 'card payment machine') prohibition from gaming venues. The setting for the studies was predominantly gaming venues $(n=6)$ or community recruitment $(n=3)$. Studies focusing on money management included one cross-sectional survey (Evans, Collard, \& Fitch, 2020) and two studies which were in-depth interviews (Heiskanen, 2017; Hing et al., 2015). Studies focusing on ATMs included two pre-post evaluations (Harrigan, MacLaren, \& Dixon, 2010; Thomas et al., 2013), two surveys (Jackson, Christensen, Francis, \& Dowling, 2016; McMillen et al., 2004) and four in-depth interviews (Allen Consulting

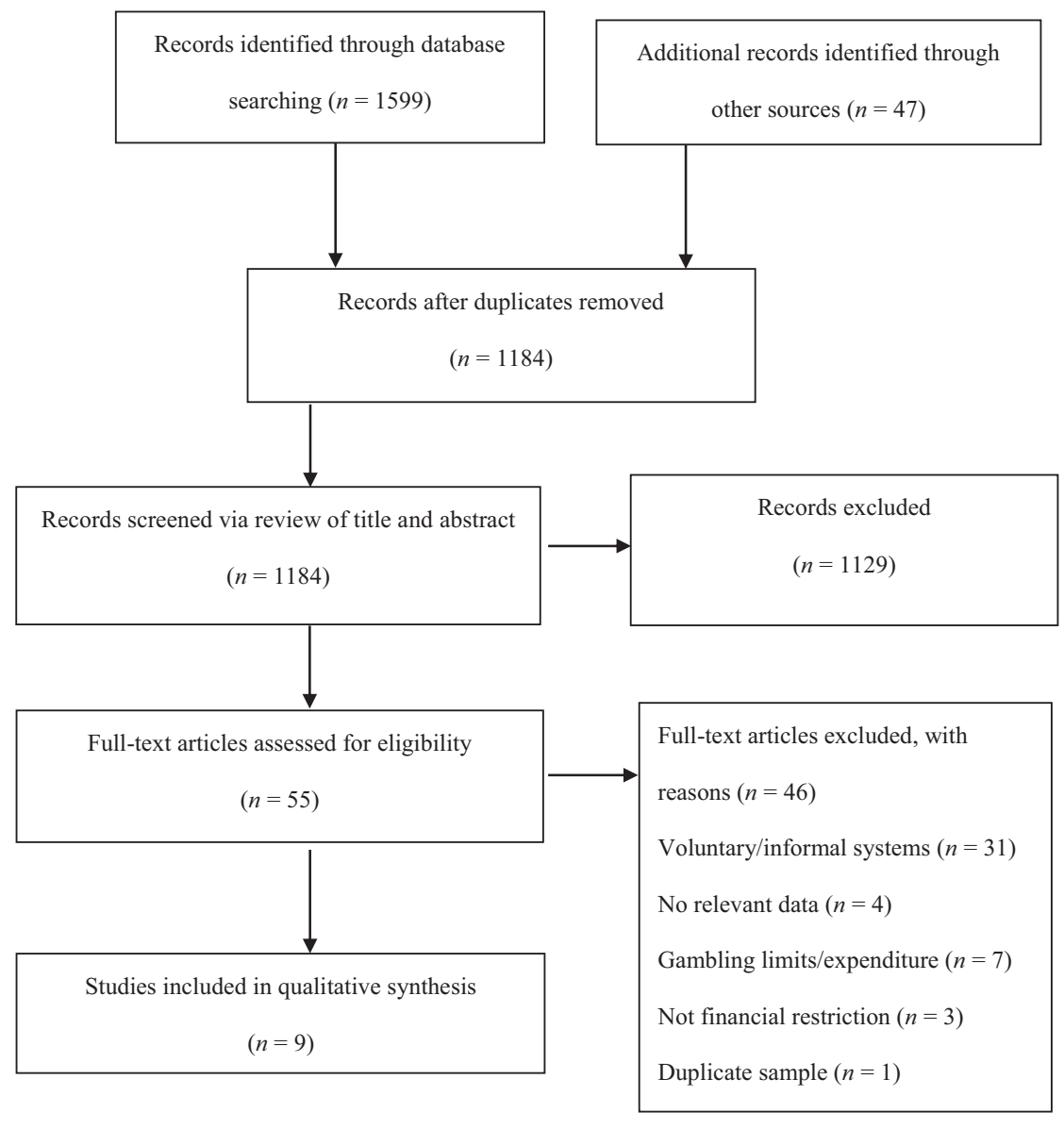

Fig. 1. Flow chart of study selection 
Group, 2011; McMillen et al., 2004; Rintoul, Deblaquiere, \& Thomas, 2017; Thomas et al., 2013) (one study was crosssectional plus interviews (McMillen et al., 2004) and another was pre-post plus interviews (Thomas et al., 2013)). Recruitment for the pre-post surveys was conducted at a gaming venue (Harrigan et al., 2010) and through community advertising and treatment services (Thomas et al., 2013). Studies involving cross-sectional surveys recruited using CATI (Computer-Assisted Telephone Interview) design (Jackson et al., 2016; McMillen et al., 2004). Recruitment for interviews was from community and treatment services (McMillen et al., 2004; Thomas et al., 2013), CATI (Allen Consulting Group, 2011) and gaming venues (Rintoul et al., 2017).

\section{Sample characteristics}

Table 1 displays the characteristics of the nine included studies. Sample sizes ranged from 17 to 928, with an average of 359 participants $)(S D=393.1$, median $=107)$. The percentage of men within the included studies ranged from $36 \%$ to $100 \%$ (average $=56.3 \%$ ). The age of participants ranged from 18 to 75 years, with an average of 35.8 years (based on five studies which reported an average age). Across the nine included studies, most recruited participants from Australia $(n=6,66.7 \%)$ with one study each from UK, Canada and Finland. The eligibility criteria related to gambling harm or involvement was most frequently selfidentified gambling problems $(n=3)$ or scoring at $3+$ (moderate risk or problem gambling) on the Problem Gambling Severity Index (PGSI) $(n=1)$. The remaining eligibility was related to frequency of gambling which included gambling or visiting a venue in the past year $(n=$ 4 ) or gambling at least twice weekly $(n=1)$. Two studies did not have any gambling-related inclusion or exclusion criteria (Allen Consulting Group, 2011; Thomas et al., 2013).

The target group(s) of these interventions varied. The three studies examining money management systems targeted three different groups and all involved samples consisting only of moderate-risk or problem gamblers. Evans et al.'s (2020) study of financial blocking systems stated that the target market was gamblers as well as affected others experiencing harm. Gamblers included anyone who attempted to self-regulate or reduce gambling behaviours, including people experiencing gambling harm (i.e., affected others). Heiskanen (2017) presented a qualitative study of financial recovery from problem gambling, with all participants being self-identified problem gamblers. Hing et al.'s (2015) study was targeted at all Internet gamblers but the final sample included only moderate-risk or problem gamblers. The target group for ATM restrictions were gaming machine gamblers in land-based venues. Four of these studies reported ATM restrictions as harm minimization measures targeting gaming venue patrons. A further two studies measuring the attitudes towards ATM restrictions stated that the measures were to support the reduction of problem gambling (McMillen et al., 2004), whereas the Harrigan et al. (2010) study examined the impact of ATM removal on gaming machine gamblers, using a sample of regular gamblers (twice weekly or more).

\section{The characteristics of hard-barrier systems and tools}

The type of hard barriers in this study were systems and tools to assist with financial management and reduction of access to money or cash for gambling. The three studies which examined money management systems or tools were related to attitudes and preferences towards prohibiting credit and debit card betting (Evans et al., 2020; Hing et al., 2015) and financial management systems that could impact on access to cash (Heiskanen, 2017). The six studies focusing on ATMs included three which examined their removal from a whole jurisdiction excluding casinos (Allen Consulting Group, 2011; Jackson et al., 2016; Thomas et al., 2013) and one that removed ATMs from one gambling venue only (Harrigan et al., 2010). One study examined attitudes towards the proposed removal of ATMs (McMillen et al., 2004) and another examined an extension of ATM removal to EFTPOS restrictions (Rintoul et al., 2017). EFTPOS was highlighted as different from ATMs in that the person must interact with an operator in order to withdraw cash.

\section{Attitudes towards hard-barrier financial systems and} tools. Three studies examined attitudes and preferences toward hard-barrier financial systems and tools designed to assist with financial management in a gambling context. Evans et al. (2020) examined the usage of debit and credit card technology to block gambling expenditure as well as preferences for banking systems in the UK that could assist in access to money or cash for gambling. The authors conducted a cross-sectional survey with 88 participants who were recruited mainly from treatment services. Participants were asked about their awareness and use of debit and credit card technology blocking options which would prevent financial transactions from occurring with businesses that provide gambling opportunities. At the time of the survey, eight financial services offered the technology on selected accounts which meant it was available to approximately $60 \%$ of people in the UK. Evans et al. (2020) reported that 43\% of treatment seekers were not aware of such financial blocking options. Of those aware of banking blocks, $44 \%$ had turned on the blocks at least once to stop or reduce gambling, and $54 \%$ reported reduced gambling expenditure and had not reverted the block. Overall, $65 \%$ of respondents rated debit and credit card blockers as a helpful way to control gambling (rating of $7 / 10$ or higher). The authors also provided data from one financial institution and reported that the blocker stopped an average of two to three transactions per user per month. They estimated that half a million people in the UK alone were currently using the blocks but just $20 \%$ reported gambling in the six months prior to the block initiation. The authors suggested that affected others may also be implementing blocks as a way of reducing gambling-related harm. Given the usefulness of money and cash blocks, the authors commented on the need to take advantage of opportunities to inform customers when opening accounts, in bank statements or where expenditure patterns may indicate 


\begin{tabular}{|c|c|c|c|c|c|}
\hline $\begin{array}{l}\text { Author, date and source } \\
\text { type }\end{array}$ & $\begin{array}{l}\text { Type and quality of } \\
\text { evidence }\end{array}$ & Study design and population ${ }^{c}$ & $\begin{array}{l}\text { Research aim relevant to the } \\
\text { current study }\end{array}$ & Key findings & Funding body \\
\hline $\begin{array}{l}\text { Allen Consulting Group } \\
\text { (2011) }\end{array}$ & $\begin{array}{l}\text { Report } \\
\text { Low }\end{array}$ & $\begin{array}{c}\text { Thirteen structured group } \\
\text { interviews, }(n=126) ; 55 \% \\
\text { male, aged } 18-70,12 \% \mathrm{MR} / \\
\text { PG. Participants were } \\
\text { recruited from a CATI survey } \\
\text { of those willing to take part in } \\
\text { an interview. }\end{array}$ & $\begin{array}{l}\text { Explore the attitudes and } \\
\text { impact of ATM removal from } \\
\text { gaming venues in Tasmania } \\
\text { (exc. casinos). }\end{array}$ & $\begin{array}{l}\text { Strong support for the removal of } \\
\text { ATMs from gaming venues as circuit } \\
\text { breaker for continued gambling once } \\
\text { limits reached. There was low support } \\
\text { for casino exemption. }\end{array}$ & $\begin{array}{c}\text { Tasmanian government } \\
\text { Australia }\end{array}$ \\
\hline Evans et al. (2020) & $\begin{array}{l}\text { Report } \\
\text { Low }\end{array}$ & $\begin{array}{c}\text { Cross-sectional survey } \\
(n=88) ; 61 \% \text { male, } 55 \% \text { were } \\
\text { 34-54 years of age. } \\
\text { Recruitment was } \\
\text { predominantly via treatment } \\
\text { services. }\end{array}$ & $\begin{array}{l}\text { Determine usage and } \\
\text { preferences for banking } \\
\text { systems that can assist in } \\
\text { reducing gambling-related } \\
\text { harm. }\end{array}$ & $\begin{array}{l}\text { Of those aware of banking blocks, } 44 \% \\
\text { had turned it on at least once to stop or } \\
\text { reduce gambling. 54\% had reduced } \\
\text { gambling expenditure and had not } \\
\text { reverted the restriction. As for ideal } \\
\text { banking system, the most endorsed } \\
\text { components were hard barriers on } \\
\text { frequency and expenditure per day; } \\
\text { limits on the time of day for card use; as } \\
\text { well as an option for a cooling off } \\
\text { period or the option for a permanent } \\
\text { block. Other potential service options } \\
\text { were highly endorsed, including a } \\
\text { regular reminder of gambling } \\
\text { expenditure each month and access to } \\
\text { gambling-harm reduction experts } \\
\text { located in financial institutions. }\end{array}$ & Gamble Aware UK \\
\hline Harrigan et al. (2010) & $\begin{array}{l}\text { Report } \\
\text { Moderate }\end{array}$ & $\begin{array}{l}\text { Pre-post study with matched } \\
\text { control ( } n=729) ; 36 \% \text { male, } \\
\text { average age } 53.5 \text { years ( } S D= \\
\text { 41.2), frequent EGM gamblers } \\
\text { recruited in venues, } 62 \% \text { MR } \\
\text { or PG. Recruited from two } \\
\text { gaming venues. }\end{array}$ & $\begin{array}{l}\text { To determine the impact of } \\
\text { removing ATMs from one } \\
\text { gaming room (versus another } \\
\text { venue where ATMs were not } \\
\text { removed) on expenditure, } \\
\text { frequency and unplanned } \\
\text { gambling. }\end{array}$ & $\begin{array}{l}\text { Removal of ATMs was associated with } \\
\text { reduced unplanned gambling on the } \\
\text { initial day of testing when compared } \\
\text { with a venue where the ATMs were not } \\
\text { removed from the gaming room floor. } \\
\text { There was no change in gambling } \\
\text { expenditure, frequency or unplanned } \\
\text { gambling between the two venues at 30- } \\
\text { day follow-up. }\end{array}$ & $\begin{array}{c}\text { GREO (formerly Ontario } \\
\text { Problem Gambling Research } \\
\text { Centre) Canada }\end{array}$ \\
\hline Heiskanen (2017) & $\begin{array}{l}\text { Journal article } \\
\text { Low }\end{array}$ & $\begin{array}{l}\text { Semi-structured interviews }(n \\
\quad=17) ; 71 \% \text { male, } M=42 \\
\text { years (range } 24-70 \text { ). Self- } \\
\text { identified gambling problems } \\
\text { recruited from treatment and } \\
\text { support services or groups. }\end{array}$ & $\begin{array}{l}\text { Investigate financial recovery } \\
\text { from problem gambling } \\
\text { including the experience of } \\
\text { community and health } \\
\text { services. }\end{array}$ & $\begin{array}{l}\text { Restrictive money-management } \\
\text { measures were perceived as effective } \\
\text { and supportive of personal aims of } \\
\text { controlling money. Viewed more } \\
\text { trustworthy when oversight was outside } \\
\text { of the family. Viewed as useful when } \\
\text { offered alongside financial advice and } \\
\text { assistance. }\end{array}$ & $\begin{array}{l}\text { Finnish Foundation for } \\
\text { Alcohol Studies. } \\
\\
\text { (continued) }\end{array}$ \\
\hline
\end{tabular}


Author, date and source type

Hing et al. (2015)

Jackson et al. (2016)

Journal article

Low

McMillen et al. (2004)

Rintoul et al. (2017)

Thomas et al. (2013) evidence

ournal article Low

Report
Type and quality of Study design and population

Semi-structured interviews ( $n$ = 25); $100 \%$ male, $M=39.9$ years $(S D=14.1), 100 \% \mathrm{MR}$ or PG on the PGSI. Recruited from previous survey participants who had gambled $>$ once in the past 12 months and were not currently seeking treatment. Cross-sectional CATI survey. Sub-sample of the 2011

Tasmanian prevalence survey, $(n=828) ; 44 \%$ male, average age 43 years, $8 \%$ MR or PG. Recruited those who had gambled on an EGM in the past 12 months.

Mixed methods. Crosssectional CATI survey $(n=$ 755 ), $49 \%$ male, $56 \%$ aged 18 44 years. Most of the sample were non-gamblers (78\%), with 11 participants selfidentified as having a gambling problem. Additional

in-depth interviews with gamblers and affected others $(n=16)$.

In-depth interviews with gamblers $(n=40)$ and three focus groups with professionals $(n=20)$. Gamblers: 50\% male, 33/40 aged 25-64 years, $84 \%$ MR or PG on PGSI. Recruited from 11 gaming venues. Moderate
Mixed methods. Pre-post survey $(n=928) ; 41 \%$ male, $M=48$ years $(S D=16.2)$ and
Research aim relevant to the current study

Key findings

Funding body

Understand aspects of

Internet gambling that are associated with loss of contro and perceived usefulness of RG measures.

Impaired control was associated with access to credit betting. Participants had concerns about credit provision from operators, ease of credit card use and inconsistency between online and landbased restrictions on credit betting.

To examine self-reported change to gambling expenditure following the removal of ATMs from Tasmanian gaming venues.

Across the whole sample there was no change to gambling expenditure. However, $10 \%$ of MR/PG decreased expenditure compared with just $4.5 \%$ of LR and $0.6 \%$ of non-problem gamblers.

Determine attitudes towards ATM removal from gaming venues in the Australian Capital Territory.

upport for removal of ATMs was 57\% across the sample, with higher rates of agreement by non-gamblers and people with gambling problems.

Interviews with gamblers and affected others reported almost unanimous support for the complete removal of ATMs from gaming venues.

The study explored access to cash in gambling venues.

A key theme was stronger regulation of access to cash in gambling venues. Unrestricted access to cash through EFTPOS had the potential to undermine the benefits of ATM removal from gaming venues.

Evaluate the effectiveness of Positive attitude towards ATM removal ATM removal from all from all gambling venues by $P G$ and to a lesser extent non-gamblers.
Gambling Research Australia.

Tasmanian government Australia.

Australian Capital Territory ACT) Gambling and Racing Commission Australia.

Commonwealth Government of Australia.

Victorian Department of Justice and the Victorian

(continued) 


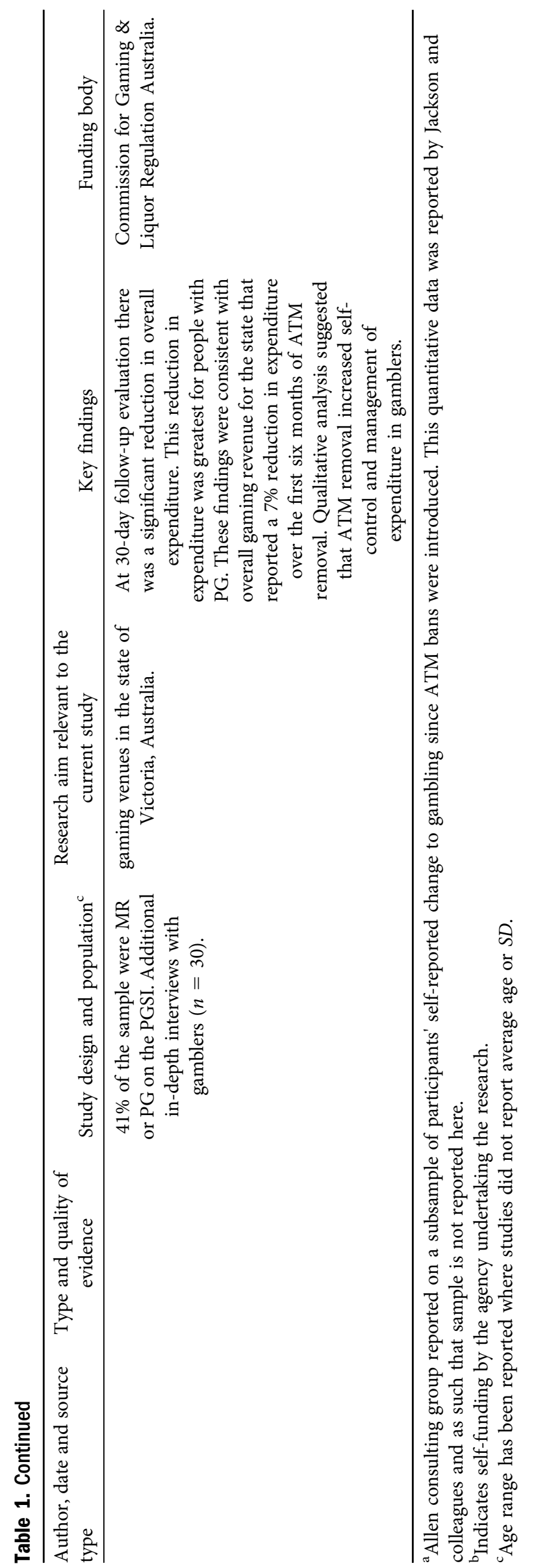

problematic gambling. Treatment and support services and self-exclusion providers should also be alerting clients to the option. For optimal effectiveness, the authors suggested card blockers may need to be implemented in conjunction with self-exclusion and/or gambling website blockers. Evans et al. (2020) also investigated the ideal components of a money management system to provide hard financial limits. Participants rated the importance of seven different potential components of a banking tool to support the selfmanagement of gambling. The highest endorsements, as determined by a score of $7 / 10$ or greater, were: " $A$ cooling off period between initiation and ability to turn off the block" (91\%); "requirement to talk to a person at the bank before being able to turn off the block" (91\%); and, "allow a permanent block on all gambling spend on the card" (91\%) Evans et al. (2020).

Heiskanen (2017) investigated factors related to financial recovery from problem gambling using the hard barriers imposed by social services versus a soft limit imposed by family member. In this study, hard barriers referred to social service being appointed to manage money and be partly or entirely responsible for the gambler's income and expenditure. The study conducted a series of semi-structured interviews with 17 participants who self-identified as having gambling problems. Heiskanen (2017) reported that financial strain often became worse after stopping gambling because of debt-related interest that continued to grow. Ongoing financial strain was associated with relapse, and hard-barrier financial systems and tools could assist with relapse prevention. Participants reported mixed experiences of having social services over a family member control money and cash. Some participants experienced relief when relapses could be prevented and when a sense of self-trust could be regained. Control over money and cash appeared to be more therapeutic than focusing on debt reduction in that some participants continued to gamble when relieved of debt. This was made worse because the only hard barriers were available through social services which was not suitable for most participants (Heiskanen, 2017).

Hing et al. (2015) conducted a study to understand aspects of Internet gambling that were associated with loss of control and attitudes towards bans to credit card betting. A total of 25 semi-structured interviews were conducted with men who were classified by the PGSI as moderate-risk or problem gamblers. Recruitment was selected participants involved in previous surveys conducted by the research team, with eligibility restricted to those who had gambled at least once in the past 12 months and were not currently seeking gambling-specific treatment. Participants voiced concerns about the convenience and accessibility of credit betting and the ease of credit card use. They stated that direct linkages between credit and betting accounts through the storage of card details meant funds could be topped up instantly. Others stated that credit betting provided access to funds to support chasing losses which inadvertently led to more desperation and chasing. Multiple participants called for a direct prohibition of credit 
betting to limit access to money for gambling. Hing et al. (2015) noted that harm-minimization measurers mandated in land-based venues were not applied to all Internet gambling operators.

Attitudes towards prohibition of ATMs in gaming venues. Five studies investigated attitudes and preferences towards restricting access to cash through ATMs in gambling venues. Allen Consulting Group (2011) explored attitudes towards the removal of ATMs from gaming venues in Tasmania (Australia). This mixed-methods study convened 13 structured group interviews and administered a questionnaire to 126 participants. Participants were recruited from a CATI survey and had indicated a willingness to take part in an interview. Twelve percent of the sample were screened as moderate-risk or problem gamblers on the PGSI. Qualitative data indicated strong support from the gamblers for the removal of ATMs because not having access to an ATM triggered a break in play and potentially helped people manage impulsive expenditure. Participants indicated a preference for the prohibition of ATMs in gambling venues to be extended to the two state-based casinos.

McMillen et al. (2004) conducted a study of attitudes towards ATM removal from gaming venues in the Australian Capital Territory (Australia). This study was a crosssectional CATI survey involving 755 participants. The sample consisted 590 (78\%) people who had not been to a gambling venue in the past 12 months (termed 'nongambler'), 119 occasional gamblers, 44 regular gamblers (defined as gambling at least weekly) and 11 participants reporting self-identified gambling problems. This data was also supplemented with interviews with 16 gamblers and affected others. CATI participants were asked to indicate the degree to which they strongly agreed to strongly disagree with four questions related to ATM removal and bans on access to money from credit cards in venues. In response to the question of whether "ATMs should be removed from gaming venues altogether", $48 \%$ either agreed or strongly agreed with ATM removal. This rate varied according to gambling status: $55 \%$ of self-identified problem gamblers and $52 \%$ of non-gamblers agreed that ATMs should be removed, compared with $35 \%$ of occasional gamblers. McMillen et al.'s (2004) qualitative component indicated strong agreement for the prohibition of ATMs by people harmed by gambling. The report stated that most people harmed by gambling supported the removal of ATMs from gambling venues.

Rintoul et al. (2017) explored venue controls for limiting access to cash. Forty gamblers were recruited from 11 gambling venues. Almost all participants reported gambling problems, with $84 \%$ scoring as moderate-risk or problem gamblers on the PGSI. Gamblers were asked to report on tools for controlling access to cash in gambling venues. Participants were concerned that removal of ATMs meant that cash could be accessed through EFTPOS and that these financial transactions were not subject to the same restrictions. Participants reported that access to cash through
EFTPOS had the potential to undermine the removal of ATMs from venues.

Thomas et al. (2013) conducted a mixed-methods study investigating attitudes and effectiveness of the removal of ATMs from gaming venues in Victoria, Australia. A total of 929 gamblers were recruited from the community and completed a pre- and post-survey on ATM removal. At baseline, very few people agreed that ATMs should be permitted in gaming areas (around 5\% agreed), with around half agreeing that they could be in gambling venues but not in gaming areas. There was a significant difference in agreement whereby $27 \%$ of people with problem gambling thought ATMs should be in venues compared with around half of non-Electronic gaming machine (EGM) gamblers or those with low-level problems. Two-thirds of people with gambling problems thought that ATMs should be removed from venues altogether, a rate which was significantly higher than found in participants with other levels of gambling risk. Thomas et al.'s (2013) interviews with gamblers indicated positive attitudes to ATM withdrawal. Qualitative analysis suggested that ATM removal would be helpful to gamblers and/or to other people. Furthermore, two-thirds of problem gamblers wanted EFTPOS removed from gambling venues altogether.

\section{The effectiveness of hard barriers}

Three studies evaluated the effectiveness of hard restrictions on cash use. All three studies were related to the removal of ATMs from gaming venues. Harrigan et al.'s (2010) pre-post study investigated the impact of removing ATMs from one gaming room. This pre-post study used a matched control design where gambling expenditure, frequency and sticking to limits were measured for patrons at two gambling venues (one where ATMs were removed from the gaming room floor and one where they were not removed). The authors recruited 729 frequent gamblers (gambling at least twice weekly) from two gambling venues in Ontario, Canada, and administered pre-post measures examining gambling expenditure and frequency at baseline and 30 days later. A small minority of the participants reported no gambling problems (16\%), with the majority classed on the PGSI as experiencing low-risk (23\%), moderate-risk (39\%) and problem gambling (23\%). Harrigan et al. (2010) reported reduced unplanned cash withdrawals on the day of the intervention (24\% of participants) compared with the control group (43\%). At a 30-day follow-up evaluation, there was no difference in expenditure, frequency or unplanned gambling. Harrigan et al. (2010) concluded that continued availability of ATMs in the venue may impact on the usefulness of removing them from the gaming floor.

Jackson et al.'s (2016) cross-sectional study examined self-reported changes in gambling expenditure following the removal of ATMs from gaming venues in Tasmania, Australia. The sample consisted 828 participants who had gambled on an EGM in the past 12 months. Participants were asked whether their gambling had increased, decreased or stayed the same since ATMs were removed from venues. 
Across the entire sample, $98 \%$ of participants reported no change in gambling expenditure. However, there was a significant difference between non-problem and gamblers at risk whereby $10 \%$ of moderate-risk and problem gamblers reported a reduction in gambling expenditure.

The largest and most extensive evaluation of ATM removal from gaming venues was conducted by Thomas et al. (2013) in Victoria, Australia. Involving 928 gamblers in a pre-post survey, Thomas and colleagues reported a significant reduction in EGM expenditure between baseline and a 30-day follow-up evaluation. People with problem gambling reported a reduction in average monthly expenditure from AUD\$277 to AUD\$187 in hotels and AUD\$203 to AUD\$161 in clubs. No difference was detected in the amount spent at casinos and racecourses which were exempt from the ATM ban. These findings were consistent with industry reports which found a $7 \%$ reduction across the state of Victoria in the six-month post evaluation period. Qualitative analysis suggested that ATM removal supported gamblers' self-control. Participants stated that ATM removal assisted people to 'think twice' about further expenditure. Some noted that ATM removal would not be enough to stop people from excessive gambling once problems had developed but that it might be useful as a way of preventing harm from occurring in the first place (Thomas et al., 2013).

\section{DISCUSSION}

This review examined the attitudes and effectiveness of systems and tools to support hard financial limits on money and cash in a gambling context. It is well established that gamblers across the continuum of gambling risk use informal systems and tools to self-regulate (Currie et al., 2020; Matheson et al., 2019; Rodda, Bagot, et al., 2018). Nonetheless, there has been a dearth of evidence on formal or hard financial systems or tools limiting money or cash use in a gambling context. Evidence on the effectiveness of such measures has also been scarce. The current scoping review identified nine studies which examined attitudes towards and/or effectiveness of financial systems or tools to limit money or cash use in a gambling context. These studies assessed debit and credit card blockers and the need for hard financial systems that can support self-regulation and recovery from gambling problems. Most studies were related to in-venue cash restrictions and all of these were associated with ATM or EFTPOS availability.

Six studies examined attitudes and impact of ATM removal from gaming venues. These studies consistently found that gamblers perceived ATM removal as helpful for sticking to gambling limits. However, these studies varied in the degree of support from gamblers for ATM removal which appeared to be influenced by the gambling context (whether ATMs had already been removed), the extent of ATM removal (a single venue versus a whole jurisdiction) and the frequency and severity of participants' gambling engagement. For example, participants in Australian studies, where ATMs had previously been removed, reported stronger support for removal than in jurisdictions where similar measures were being proposed. As for effectiveness, where ATMs were removed from whole gambling areas, there were reports of reduced gambling especially amongst those with gambling problems. The only study which analysed the removal of ATMs from a single venue reported no impact on gambling expenditure or time spent gambling (Harrigan et al., 2010). This suggests that restrictions need to be applied across jurisdictions or countries to ensure that they have a chance of being effective.

Across the included studies, just one examined hard financial systems and tools for Internet gambling (Hing et al., 2015). This study questioned the inconsistency in financial restrictions between land-based and Internet gambling. The growth of remote gambling globally places an even greater emphasis on the potential for hard-barrier systems and tools to limit gambling, and for the financial sector to make such measures available in consultation with the gambling sector and policymakers. This review recognizes that harm-minimization measures in land-based venues are not consistently applied to Internet gambling operators. Therefore, evidence on effective hard barriers for remote operators is rapidly needed. Furthermore, systems and tools that operate only in land-based gambling venues may exacerbate inequalities in gambling harms if hard barriers such as limiting access to ATMs are not accompanied by hard financial barriers online. Internet gambling is growing rapidly, particularly during the COVID-19 pandemic (Håkansson, Fernández-Aranda, Menchón, Potenza, \& Jiménez-Murcia, 2020). Because of the rapid growth in online gambling, there is an urgent need to extend hard barriers into Internet gambling to restrict access to funds as well as to introduce new hard barriers specifically for Internet gambling.

\section{Limitations}

The quality of included studies was low. Only two studies involved any kind of outcome evaluation (Harrigan et al., 2010; Thomas et al., 2013). Traditional conceptions of the hierarchy of evidence ranked the quality of evidence identified in this review as low. The gap in the evidence base on this subject is a key finding of the review in itself but does undermine the generalisability of the findings to broader contexts. Similarly, included studies almost exclusively relied on self-report data. Future studies would ideally include objective financial data obtained through gambling or banking transactions. Second, the literature spans more than 20 years, encompassing major shifts in banking systems and tools, which may mean that some of the findings may no longer be relevant. For example, Evans et al. (2020) noted that the UK government recently regulated to prevent credit card betting, which somewhat negated the authors' findings related to credit betting. Similarly, the move towards cashless payments varied across countries, with this trend accelerating over time. It is possible that these changes render older studies less useful, suggesting a need to ensure 
regular monitoring of developments in this area of gambling. Finally, because of the limited number and quality of included studies, a systematic review or meta-analysis was not conducted. It is therefore not possible to draw firm conclusions as to the impact of hard financial limits on reducing money or cash for gambling or whether it had an impact on gambling-related harm.

\section{CONCLUSION}

This scoping review identified nine studies that examined attitudes and preferences of gamblers and their families to limit or restrict access to money and cash in a gambling context, as well as the effectiveness of hard financial limits that can be implemented to accomplish that goal. Overall, the literature on this topic was scant. This review provides information on where more research is needed and possible future directions for implementing hard barriers on gambling expenditure. The number of excluded full-text qualitative studies that made no mention of hard financial limits was surprising. Future research might consider how and why the situation has developed in which counsellors, academics, governments and policymakers are not demanding that financial systems and tools be put in place to protect and support gamblers and their families. Interestingly, there was also very little discussion in the included studies as to why there was so little research on hard financial limits.

The current findings suggest an opportunity for financial institutions, gambling venues and policymakers to unilaterally act to prevent and reduce unrestricted access to money and cash by people who are concerned about gambling harm. Financial institutions are in a position to deliver public good products that can make a massive impact on individuals and families in a gambling context. Ideally researchers could partner with financial institutions to evaluate and report on the impact of these measures. The gambling field is in a unique position to advocate on behalf of other health and social services for systems and tools that can help many different segments of the population suffering from gambling-related harms.

Funding sources: This research was conducted with funding from Gambling Research Exchange Ontario Canada. GREO worked with the author to refine and apply the search strategy and arranged independent peer review of a previous version of the manuscript. The funding body GREO had no influence in the decision to submit the paper for publication.

Conflict of interest: The author has no conflict of interest to declare in relation to this article. The 3-year declaration of interest statement of this research team is as follows: I have received funding from multiple sources, including government departments and New Zealand Ministry of Health, Gambling Research Exchange Ontario and Victorian
Responsible Gambling Foundation (through hypothecated taxes from gambling revenue). I have not knowingly received research funding from the gambling, tobacco, or alcohol industries or any industry-sponsored organisation.

Acknowledgment: Thank you to Natalia Booth for assistance with data extraction and Dr Severi Luoto with editing the final manuscript. Thank you to Margo Hilbrecht and the anonymous peer reviewers for their feedback on this manuscript.

\section{REFERENCES}

Allen Consulting Group. (2011). Social and economic impact study of gambling in Tasmania. Melbourne: Allen Consulting Group.

Barnard, M., Kerr, J., Kinsella, R., Orford, J., Reith, G., \& Wardle, H. (2014). Exploring the relationship between gambling, debt and financial management in Britain. International Gambling Studies, 14(1), 82-95. https://doi.org/10.1080/14459795.2013. 842606.

Blaszczynski, A., Collins, P., Fong, D., Ladouceur, R., Nower, L., Shaffer, H. J., \& Venisse, J.-L. (2011). Responsible gambling: General principles and minimal requirements. Journal of Gambling Studies, 27(4), 565-573. https://doi.org/10.1007/ s10899-010-9214-0.

Blaszczynski, A., Shaffer, H. J., Ladouceur, R., \& Collins, P. (2021). Clarifying responsible gambling and its concept of responsibility. International Journal of Mental Health and Addiction, 1-7. https://doi.org/10.1007/s11469-020-00451-5.

Booth, N., Dowling, N. A., Landon, J., Lubman, D. I., Merkouris, S. S., \& Rodda, S. N. (2021). Affected others responsivity to gambling harm: An international taxonomy of consumerderived behaviour change techniques. Journal of Clinical Medicine, 10(4), 583. https://doi.org/10.3390/jcm10040583.

Colquhoun, H. L., Levac, D., O’Brien, K. K., Straus, S., Tricco, A. C., Perrier, L., \& Moher, D. (2014). Scoping reviews: Time for clarity in definition, methods, and reporting. Journal of Clinical Epidemiology, 67(12), 1291-1294. https://doi.org/10.1016/j. jclinepi.2014.03.013.

Côté, M., Tremblay, J., Jiménez-Murcia, S., Fernàndez-Aranda, F., $\&$ Brunelle, N. (2019). How can partners influence the gambling habits of their gambler spouse? Journal of Gambling Studies, 1-26. https://doi.org/10.1007/s10899-019-09917-1.

Currie, S. R., Brunelle, N., Dufour, M., Flores-Pajot, M. C., Hodgins, D., Nadeau, L., \& Young, M. (2020). Use of self-control strategies for managing gambling habits leads to less harm in regular gamblers. Journal of Gambling Studies, 36(2), 685-698. https://doi.org/10.1007/s10899-019-09918-0.

Delfabbro, P., \& King, D. L. (2020). On the limits and challenges of public health approaches in addressing gambling-related problems. International Journal of Mental Health and Addiction, 18(3), 844-859. https://doi.org/10.1007/s11469-02000276-2.

Drawson, A. S., Tanner, J., Mushquash, C. J., Mushquash, A. R., \& Mazmanian, D. (2017). The use of protective behavioural 
strategies in gambling: A systematic review. International Journal of Mental Health and Addiction, 15(6), 1302-1319. https://doi.org/10.1007/s11469-017-9754-y.

Evans, D. (2003). Hierarchy of evidence: A framework for ranking evidence evaluating healthcare interventions. Journal of Clinical Nursing, 12(1), 77-84. https://doi.org/10.1046/j.1365-2702. 2003.00662.x.

Evans, J., Collard, S., \& Fitch, C. (2020). A blueprint for bank card gambling blockers. Retrieved from Bristol, UK: http://www. bristol.ac.uk/media-library/sites/geography/pfrc/A\% $20 \mathrm{Blueprint} \% 20$ for $\% 20 \mathrm{Bank} \% 20 \mathrm{Card} \% 20 \mathrm{Gambling} \%$ 20Blockers\%20-\%20Report.pdf.

Evans, L., \& Delfabbro, P. H. (2005). Motivators for change and barriers to help-seeking in Australian problem gamblers. Journal of Gambling Studies, 21(2), 133-155. https://doi.org/10. 1007/s10899-005-3029-4.

Forsström, D., Spångberg, J., Petterson, A., Brolund, A., \& Odeberg, J. (2020). A systematic review of educational programs and consumer protection measures for gambling: An extension of previous reviews. Addiction Research \& Theory, 1-15. https:// doi.org/10.1080/16066359.2020.1729753.

Gambling Commission. (2020). Changes to licence conditions and codes of practice on the use of credit cards for gambling: Consultation response. Retrieved from Birmingham, UK: https://www.gamblingcommission.gov.uk/PDF/Consultationresponses-2020/Credit-card-responses-document-final-for-thepdf-version.pdf.

Gambling Research Exchange Ontario. (2020). The role of credit cards in gambling. Retrieved from Birmingham, UK: https:// doi.org/10.33684/2020.001.

Granero, R., Blaszczynski, A., Fernández-Aranda, F., Gómez-Peña, M., Moragas, L., Aymamí, N., ... Jiménez-Murcia, S. (2020). Does money control enhance the effectiveness of CBT for gambling disorder? International Journal of Mental Health and Addiction. https://doi.org/10.1007/s11469-019-00212-z.

Håkansson, A., Fernández-Aranda, F., Menchón, J. M., Potenza, M. N., \& Jiménez-Murcia, S. (2020). Gambling during the COVID19 crisis-a cause for concern. Journal of Addiction Medicine, 14(4), e10. https://doi.org/10.1097/ADM.0000000000000690.

Håkansson, A., \& Widinghoff, C. (2020). Over-indebtedness and problem gambling in a general population sample of online gamblers. Frontiers in Psychiatry, 11. https://doi.org/10.3389/ fpsyt.2020.00007.

Harrigan, K. A., MacLaren, V. V., \& Dixon, M. J. (2010). Effectiveness of a brief educational intervention and ATM-removal in reducing erroneous cognitions and over-expendicture during slot machine play in problem and non-problem gamblers. Retrieved from Guelph, ON: https://www.greo.ca/Modules/ EvidenceCentre/files/Harrigan\%20et\%20al(2010)Effectiveness_ of_a_brief_educational_intervention.pdf.

Heiskanen, M. (2017). Financial recovery from problem gambling: Problem gamblers' experiences of social assistance and other financial support. Journal of Gambling Issues, 2017(35), 24-48. https://doi.org/10.4309/jgi.2017.35.2.

Hing, N., Cherney, L., Gainsbury, S. M., Lubman, D. I., Wood, R. T., \& Blaszczynski, A. (2015). Maintaining and losing control during internet gambling: A qualitative study of gamblers' experiences. New Media and Society, 17(7), 1075-1095. https:// doi.org/10.1177/1461444814521140.

Hing, N., Russell, A. M. T., \& Hronis, A. (2017). What behaviours and cognitions support responsible consumption of gambling? Results from an expert survey. International Journal of Mental Health and Addiction, 15(6), 1320-1341. https://doi.org/10. 1007/s11469-017-9793-4.

Hing, N., Sproston, K., Tran, K., \& Russell, A. M. T. (2017). Gambling responsibly: Who does it and to what end? Journal of Gambling Studies, 33(1), 149-165. https://doi.org/10.1007/ s10899-016-9615-9.

Hodgins, D. C., \& El-Guebaly, N. (2004). Retrospective and prospective reports of precipitants to relapse in pathological gambling. Journal of Consulting and Clinical Psychology, 72(1), 72-80. https://doi.org/10.1037/0022-006x.72.1.72.

Jackson, A. C., Christensen, D. R., Francis, K. L., \& Dowling, N. A. (2016). Consumer perspectives on gambling harm minimisation measures in an Australian jurisdiction. Journal of Gambling Studies, 32(2), 801-822. https://doi.org/10.1007/ s10899-015-9568-4.

Kalischuk, R. G., Nowatzki, N., Cardwell, K., Klein, K., \& Solowoniuk, J. (2006). Problem gambling and its impact on families: A literature review. International Gambling Studies, 6(1), 31-60. https://doi.org/10.1080/14459790600644176.

Kourgiantakis, T., Saint-Jacques, M.-C., \& Tremblay, J. (2013). Problem gambling and families: A systematic review. Journal of Social Work Practice in the Addictions, 13(4), 353-372. https:// doi.org/10.1080/1533256X.2013.838130.

Krishnan, M., \& Orford, J. (2002). Gambling and the family: From the stress-coping-support perspective. International Gambling Studies, 2(1), 61-83. https://doi.org/10.1080/ 14459790208732300.

Ladouceur, R., Shaffer, P., Blaszczynski, A., \& Shaffer, H. J. (2017). Responsible gambling: A synthesis of the empirical evidence. Addiction Research \& Theory, 25(3), 225-235. https://doi.org/ 10.1080/16066359.2016.1245294.

Ledgerwood, D. M., Wiedemann, A. A., Moore, J., \& Arfken, C. L. (2012). Clinical characteristics and treatment readiness of male and female problem gamblers calling a state gambling helpline. Addiction Research \& Theory, 20(2), 162-171. https://doi.org/ 10.3109/16066359.2011.588815.

Lostutter, T. W., Lewis, M. A., Cronce, J. M., Neighbors, C., \& Larimer, M. E. (2014). The use of protective behaviors in relation to gambling among college students. Journal of Gambling Studies, 30(1), 27-46. https://doi.org/10.1007/s10899012-9343-8.

Lucar, C., Wiebe, J., \& Philander, K. S. (2013). Monetary limits tools for internet gamblers: A review of their availability, implementation and effectiveness online. Retrieved from Toronto, ON: https://www.greo.ca/Modules/EvidenceCentre/files/ Lucar\%20et\%20al(2012)Review_of_monetary_limit_tools_for_ Internet_gamblers.pdf.

Matheson, F. I., Hamilton-Wright, S., Kryszajtys, D. T., Wiese, J. L., Cadel, L., Ziegler, C., ... Guilcher, S. J. T. (2019). The use of self-management strategies for problem gambling: A scoping review. BMC Public Health, 19(1). https://doi.org/10.1186/ s12889-019-6755-8. 
McMahon, N., Thomson, K., Kaner, E., \& Bambra, C. (2019). Effects of prevention and harm reduction interventions on gambling behaviours and gambling related harm: An umbrella review. Addictive Behaviors, 90, 380-388. https://doi.org/10. 1016/j.addbeh.2018.11.048.

McMillen, J., Marshall, D., \& Murphy, L. (2004). The use of ATMs in ACT gaming venues: An empirical study. Retrieved from Canberra, Australia: https://openresearch-repository.anu.edu. au/handle/1885/45187.

Moher, D., Liberati, A., Tetzlaff, J., \& Altman, D. G. (2009). Preferred reporting items for systematic reviews and meta-analyses: The PRISMA statement. PLoS Medicine, 6(7), e1000097. https://doi.org/10.1371/journal.pmed.

Muggleton, N., Parpart, P., Newall, P., Leake, D., Gathergood, J., \& Stewart, N. (2021). The association between gambling and financial, social and health outcomes in big financial data. Nature Human Behaviour, 5(3), 319-326. https://doi.org/10. 1038/s41562-020-01045-w.

O’Brien, C. P., Childress, A. R., McLellan, T., \& Ehrman, R. (1990). Integrating systematic cue exposure with standard treatment in recovering drug dependent patients. Addictive Behaviors, 15(4), 355-365. https://doi.org/10.1016/0306-4603(90)90045-Y.

Oakes, J., Pols, R., \& Lawn, S. (2020). The frantic seeking of credit during poker machine problem gambling: A public health perspective. International Journal of Environmental Research and Public Health, 17(14), 1-12. https://doi.org/10.3390/ ijerph17145216.

Oksanen, A., Savolainen, I., Sirola, A., \& Kaakinen, M. (2018). Problem gambling and psychological distress: A cross-national perspective on the mediating effect of consumer debt and debt problems among emerging adults. Harm Reduction Journal, 15(1), 45. https://doi.org/10.1186/s12954-018-0251-9.

Peters, M. D., Godfrey, C. M., Khalil, H., McInerney, P., Parker, D., \& Soares, C. B. (2015). Guidance for conducting systematic scoping reviews. JBI Evidence Implementation, 13(3), 141-146. https://doi.org/10.1097/XEB.0000000000000050.

Pickering, D., Keen, B., Entwistle, G., \& Blaszczynski, A. (2018). Measuring treatment outcomes in gambling disorders: A systematic review. Addiction, 113(3), 411-426. https://doi.org/10. 1111/add.13968.

Procter, L., Angus, D. J., Blaszczynski, A., \& Gainsbury, S. M. (2019). Understanding use of consumer protection tools among internet gambling customers: Utility of the theory of planned behavior and theory of reasoned action. Addictive Behaviors, 99. https://doi.org/10.1016/j.addbeh.2019.106050.

Pulford, J., Bellringer, M., Abbott, M., Clarke, D., Hodgins, D., \& Williams, J. (2009). Reasons for seeking help for a gambling problem: The experiences of gamblers who have sought specialist assistance and the perceptions of those who have not. Journal of Gambling Studies, 25(1), 19-32. https://doi.org/10. 1007/s10899-008-9112-x.

Rintoul, A., Deblaquiere, J., \& Thomas, A. (2017). Responsible gambling codes of conduct: Lack of harm minimisation intervention in the context of venue self-regulation. Addiction Research and Theory, 25(6), 451-461. https://doi.org/10.1080/ 16066359.2017.1314465.

Rodda, S. N., Bagot, K. L., Cheetham, A., Hodgins, D. C., Hing, N., \& Lubman, D. I. (2018). Types of change strategies for limiting or reducing gambling behaviors and their perceived helpfulness: A factor analysis. Psychology of Addictive Behaviors, 32(6), 679688. https://doi.org/10.1037/adb0000393.

Rodda, S. N., Bagot, K. L., Manning, V., \& Lubman, D. I. (2019a). "It was terrible. I didn't set a limit": Proximal and distal prevention strategies for reducing the risk of a bust in gambling venues. Journal of Gambling Studies, 35(4), 1407-1421. https:// doi.org/10.1007/s10899-019-09829-0.

Rodda, S. N., Bagot, K. L., Manning, V., \& Lubman, D. I. (2019b). 'Only take the money you want to lose' strategies for sticking to limits in electronic gaming machine venues. International Gambling Studies, 19(3), 489-507. https://doi.org/10.1080/ 14459795.2019.1617330.

Rodda, S. N., Hing, N., Hodgins, D. C., Cheetham, A., Dickins, M., \& Lubman, D. I. (2017). Change strategies and associated implementation challenges: An analysis of online counselling sessions. Journal of Gambling Studies, 33(3), 955-973. https:// doi.org/10.1007/s10899-016-9661-3.

Rodda, S. N., Hing, N., Hodgins, D. C., Cheetham, A., Dickins, M., \& Lubman, D. I. (2018). Behaviour change strategies for problem gambling: An analysis of online posts. International Gambling Studies, 18(3), 420-438. https://doi.org/10.1080/ 14459795.2018.1432670.

Rosen, M. I., Bailey, M., \& Rosenheck, R. R. (2003). Alcohol \& drug abuse: Principles of money management as a therapy for addiction. Psychiatric Services, 54(2), 171-173. https://doi.org/ 10.1176/appi.ps.54.2.171.

Rosen, M. I., Carroll, K. M., Stefanovics, E., \& Rosenheck, R. A. (2009). A randomized controlled trial of a money managementbased substance use intervention. Psychiatric Services, 60(4), 498-504. https://doi.org/10.1176/ps.2009.60.4.498.

Sacco, P., Frey, J. J., Callahan, C., Hochheimer, M., Imboden, R., \& Hyde, D. (2019). Feasibility of brief screening for at-risk gambling in consumer credit counseling. Journal of Gambling Studies, 35(4), 1423-1439. https://doi.org/10.1007/s10899-01909836-1.

Shaner, A., Eckman, T. A., Roberts, L. J., Wilkins, J. N., Tucker, D. E., Tsuang, J. W., \& Mintz, J. (1995). Disability income, cocaine use, and repeated hospitalization among schizophrenic cocaine abusers-a government-sponsored revolving door? New England Journal of Medicine, 333(12), 777-783. https:// doi.org/10.1056/NEJM199509213331207.

Suurvali, H., Hodgins, D. C., \& Cunningham, J. A. (2010). Motivators for resolving or seeking help for gambling problems: A review of the empirical literature. Journal of Gambling Studies, 26(1), 1-33. https://doi.org/10.1007/s10899-0099151-y.

Suurvali, H., Hodgins, D. C., Toneatto, T., \& Cunningham, J. A. (2012). Motivators for seeking gambling-related treatment among Ontario problem gamblers. Journal of Gambling Studies, 28(2), 273-296. https://doi.org/10.1007/s10899-0119268-7.

Swanton, T. B., \& Gainsbury, S. M. (2020a). Debt stress partly explains the relationship between problem gambling and comorbid mental health problems. Social Science \& Medicine, 265, 113476. https://doi.org/10.1016/j.socscimed.2020.113476.

Swanton, T. B., \& Gainsbury, S. M. (2020b). Gambling-related consumer credit use and debt problems: A brief review. Current 
Opinion in Behavioural Sciences, 31, 21-31. https://doi.org/10. 1016/j.cobeha.2019.09.002.

Swanton, T. B., Gainsbury, S. M., \& Blaszczynski, A. (2019). The role of financial institutions in gambling. International Gambling Studies, 19(3), 377-398. https://doi.org/10.1080/ 14459795.2019.1575450.

Tanner, J., Drawson, A. S., Mushquash, C. J., Mushquash, A. R., \& Mazmanian, D. (2017). Harm reduction in gambling: A systematic review of industry strategies. Addiction Research \& Theory, 25(6), 485-494. https://doi.org/10.1080/16066359.2017.1310204.

Thomas, A., Pfeifer, J., Moore, S., Meyer, D., Yap, L., \& Armstrong, A. (2013). Evaluation of the removal of ATMs from gaming venues in Victoria, Australia. Retrieved from Melbourne: https://webarchive.nla.gov.au/awa/20140108232200/http:// pandora.nla.gov.au/pan/144043/20140109-1022/assets.justice. vic.gov.au/justice/resources/f4dc0ec8-3940-4099-8d0d0b01616470b6/atmevaluationreport.pdf.

Walker, M., Toneatto, T., Potenza, M. N., Petry, N., Ladouceur, R., Hodgins, D. C., \& Blaszczynski, A. (2006). A framework for reporting outcomes in problem gambling treatment research: The Banff, Alberta Consensus. Addiction, 101(4), 504-511. https://doi.org/10.1111/j.1360-0443.2005.01341.x.

Williams, R. J., Volberg, R. A., Stevens, R. M., Williams, L. A., \& Arthur, J. N. (2017). The definition, dimensionalization, and assessment of gambling participation. Canadian Consortium for Gambling Research. 